\title{
A Techno-Economic Investigation on Hydrogen Utilization as a Long-term Energy Storage Solution for Microgrids
}

\author{
Sharika Manjuma Islam ( $\square$ sharikamanjuma312@gmail.com ) \\ Ahsanullah University of Science and Technology, Bangladesh \\ Sambit Al Ferdous \\ Ahsanullah University of Science and Technology, Bangladesh \\ A.M Shamsur Rahman Bhuyan \\ Ahsanullah University of Science and Technology, Bangladesh \\ Syeda Maria Sultana \\ Ahsanullah University of Science and Technology, Bangladesh \\ Sunit Sarker \\ Ahsanullah University of Science and Technology, Bangladesh \\ Taskin Jamal ( $\boldsymbol{D}$ t.jamal.eee@aust.edu ) \\ Ahsanullah University of Science and Technology, Bangladesh https://orcid.org/0000-0002-6874-9371
}

\section{Research Article}

Keywords: renewable energy, Hydrogen, storage system, hybrid system, standalone microgrid

Posted Date: October 25th, 2021

DOI: https://doi.org/10.21203/rs.3.rs-1008208/v1

License: (1) This work is licensed under a Creative Commons Attribution 4.0 International License. Read Full License 


\section{Abstract}

The study aims to demonstrate a standalone PV-Hydrogen-battery microgrid's technical and economic merits in a developing country. Besides having fossil fuel resources, enough renewable energy resources have been deployed in the microgrid to create a sustainable system. The primary renewable energy resource explored is the solar PV system. The diesel-powered generators are integrated to support the system stability in high PV penetration scenarios. In such cases, energy storage options are integrated to store excess electricity, provide sufficient days of autonomy, system stability and virtual inertia. Li-ion based batteries and Hydrogen have received widespread acceptance as a potential renewable energy storage solution for coping with the variability nature of renewable energy resources. In this study, the system is optimized based on the seasonal load and real-life market information. The results reveal that a diesel-PV-Hydrogenbattery microgrid is an efficient and cost-effective configuration for remote communities in Bangladesh.

\section{Introduction}

The primary energy consumption has been increasing worldwide, approximately $2 \%$ per year [1]. The majority of the electric power generated from burning fossil fuels causes global warming and other aspects of climate change. On the other hand, the ongoing expansion of the world population and economy, in tandem with rapid urbanization, has resulted in an enormous increase in energy demand [2]. The traditional energy supply trend depends on fossil fuel-based resources limited by geographical distribution and extraction simplicity [3]. The hunt for clean energy resources is thus gaining prominence due to environmental concerns and sustainability features. Renewable Energy (RE) is one of the most acceptable sources of clean energy that have a shallow environmental impact compared to conventional sources of energy. Traditional energy sources are finite and would deplete one day, but renewable energy sources would never run out.

One of the most abundant and extensively distributed renewable energy sources is solar energy. Where grid-connectivity is not available, people in off-grid areas are increasingly opting for distributed solar photovoltaic (PV) systems to satisfy their power demands [4]. With the continued shift to renewable and yet intermittent energy sources such as solar, it is becoming clear that new methods of storing electrical energy to balance supply and demand are required [5]. Hydrogen storage would play a key role in lowering dependency on fossil fuels by allowing more renewable energy sources to be integrated [6]. Among some of the key benefits offered by microgrids are compatible integration of renewable energy resources and various storage choices. A Hydrogen-microgrid can maximize the utilization of RE resources using electrolyzers and fuel cell technologies, with any excess energy being stored and utilized during periods of low supply and high demand. Hydrogen is an ideal companion since it has a high energy density and a low carbon impact when stored.

Bangladesh is one of the world's most populous countries. The current government is committed to ensure that all citizens have access to affordable and reliable electricity by 2021 [7]. As a result, supplying electricity throughout the country that is not only based on fossil fuelbased generators but also relies on RE to reduce pollution is a significant challenge [8]. In Bangladesh, approximately $96 \%$ of grid electricity is generated using fossil fuels [9]. Bangladesh's geographical position, which offers a large quantity of sunshine, is particularly encouraging for the application of solar energy. Even though the adoption of renewable energy technologies has become a global trend, the central and local utilities in Bangladesh are still lagging in facilitating the considerable uptake of RE sources [10].

In this research, a standalone microgrid has been studied for a remote community/ a small town in Bangladesh, employing solar PV systems and other micro-sources and Hydrogen as a storage medium. The study has been motivated by system simulation from the Hybrid Optimization Model for Electric Renewables (HOMER), used for the system's long-term optimization and techno-economic feasibility analysis.

\section{The Proposed System}

The standalone microgrid considers solar PV systems to be the primary supply source. Due to the output variability nature of PV systems, the electricity generation stream solely operating with PV systems would pose technical threats to the system stability and reliability. Hence, to enhance the system performance, a hybrid generation facility has been considered.

Electrification in remote areas is becoming increasingly popular through the use of solar PV systems and energy storage devices [11]. Hydrogen-based technology has gained not only widespread acceptance as a possible large-scale energy storage option for dealing with the variability nature of renewable energy resources but also achieved tremendous progress as an energy carrier for transitioning the energy industry to a net-zero-emissions state worldwide [12]. Additionally, the lifetime of hydrogen storage is much higher than batteries 
[13]. Hence, in this research, the use of Hydrogen as the primary energy storage medium has been explored for a remote microgrid, and the consequential techno-economic impacts have been analyzed.

There have been numerous research studies conducted on battery-based PV systems for remote regions in developing countries. Hence, in this study, the use of batteries has not been overlooked, instead kept in the system configuration to analyze the system response, which might bring financial and technical benefits to the system. Li-ion based batteries are well-known as fast frequency response batteries and offer virtual inertia [14]. During emergencies or in cases where a rapid power supply is required in response to a power supply failure, diesel generators may fail to turn ON immediately or ramp up the output as needed. Li-ion based batteries are well-proven technology to immediately take over and rapidly respond to the power requirements [15].

This study considers the energy required for the electrolysis in the Hydrogen generation plant, and the charging of the batteries would occur from the excess electricity of the microgrid, which would predominantly come from PV systems. However, during unfavourable weather conditions, the PV systems may not provide enough energy for the system. In such cases, when the storage outputs would run out, the diesel-based generators would provide the necessary supply.

With the above-mentioned electricity generation philosophy, the microgrid consisting of solar PV arrays, diesel generators, electrolyzer, fuel cell, Hydrogen tank \& Li-ion batteries have been modelled using the microgrid planning tool HOMER Pro. System optimization and technoeconomic study have been carried out using the tool. Two crucial decision making criteria have influenced the optimal system design - the cost of energy (COE) and excess electricity (ECE) of the system. Few design combinations were thoroughly investigated in order to provide the best solutions for the remote community.

\section{Design Concept And System Components}

The proposed system considers the reliability of the supply stream to be of utmost concern, i.e., the community has constant access to electricity. Li-ion batteries and Power-to-Hydrogen-to-Power (P2H2P) systems were regarded as energy storage systems that not only provided power in the absence of PV and but also assisted in overcoming the weather-oriented PV output variability and uncertainties.

The objective functions of the study are to minimize the levelized COE and ECE while maximizing the RE penetration by meeting the technical and financial constraints. Hence, several system configurations/designs were explored, analyzed, and compared using performance indicators - COE and ECE. The schematic diagram of the proposed system configuration has been outlined in Fig 1. A brief depiction of the site selection and associated technology measures have been discussed, as follows.

\section{A. Location}

The remote location considered for system design study is in Pirozali, Gazipur, near Dhaka, Bangladesh. It covers 31 square kilometres and has a population of 40 thousand people (approximately). Fig. 2 shows the site area. It includes ten villages \& roughly 11,378 households. [16]. The types of electricity customers include general residential, a few institutional \& commercial. The climate in this region is temperate, with an average annual temperature of $35^{\circ} \mathrm{C}$. For electricity access, currently, the area is entirely reliant on the national grid, which often faces load shedding related reliability and power quality issues. With so many small to medium-sized industries in the area, the electricity demand is always present and predicted to increase in future.

\section{B. Load Estimation}

Extensive background studies on remote area livelihood lead to the load modelling for the community. Each general household has been considered to have five lights, four fans, and one of each of the following: TV, refrigerator, computer, oven and air conditioner. In addition, relevant commercial load profiles were considered. The seasonal variation of electricity demand considered the variations in summer, rainy season, and winter. It has been found that the annual peak occurs during August, which amounted to be $402.23 \mathrm{~kW}$. The yearly average load is around $331.18 \mathrm{~kW}$, with a load factor of 0.82 . In the load model, an amount of $408 \mathrm{~kW}$ of peak load has been assigned based on a daily load fluctuation of $1 \%$. Fig. 3 showcases the annual (a) and hourly (b) average daily load profile.

\section{Load Estimation}

Extensive background studies on remote area livelihood lead to the load modelling for the community. Each general household has been considered to have five lights, four fans, and one of each of the following: TV, refrigerator, computer, oven and air conditioner. In addition, relevant commercial load profiles were considered. The seasonal variation of electricity demand considered the variations in summer, rainy season, and winter. It has been found that the annual peak occurs during August, which amounted to be $402.23 \mathrm{~kW}$. The yearly 
average load is around $331.18 \mathrm{~kW}$, with a load factor of 0.82 . In the load model, an amount of $408 \mathrm{~kW}$ of peak load has been assigned based on a daily load fluctuation of $1 \%$. Fig. 3 showcases the annual (a) and hourly (b) average daily load profile.

\section{Solar Irradiance Profile}

The data for the global horizontal irradiance $(\mathrm{GHI})$ and the sky clearness index (SCl) were obtained from NASA's Atmospheric Science Data Centre [17]. For the selected site, the yearly average solar irradiation is about $4.64 \mathrm{kWh} / \mathrm{m}^{2} /$ day. Solar irradiance reaches as high as $5.86 \mathrm{kWh} / \mathrm{m}^{2} /$ day (average) in April, the sunniest month of the year, while it is only approximately $3.82 \mathrm{kWh} / \mathrm{m}^{2} /$ day (average) in September. The average clearness index is 0.522 . The optimum title angle for PV arrays has been decided to be 25 degrees. Fig. 4 shows the yearly average monthly solar irradiance.

\section{E. Diesel Generator(DG)}

A generic diesel generator model has been employed in the design process. The generator's capacity was kept within the range of $790 \mathrm{~kW}$ to $1000 \mathrm{~kW}$ for conducting the system optimization study. It is expected that the generators would run at a 0.8 power factor on average. The generator's minimum runtime and minimum load ratio were chosen as 30 minutes and $20 \%$, respectively.

\section{F. Electrolyzer}

The electrolyzer, hydrogen storage, and fuel cell are the three major components of the $\mathrm{P} 2 \mathrm{H} 2 \mathrm{P}$ systems. It has been considered in this study to generate Hydrogen from the excess electricity present in the system. For such, the PEM electrolyzer has been chosen. The PEM electrolyzer has maturity and appropriateness for acceptable efficiency at partial and complete load and quick response to input/output power fluctuations [12]. The electrolysis process can be expressed according to Eq. 1.

$$
\begin{aligned}
& \text { Anode reaction : } 2 \mathrm{H}_{2} \mathrm{O}=4 \mathrm{H}^{+}+4 \mathrm{e}^{-}+\mathrm{O}_{2} \\
& \text { Cathode reaction: } 4 \mathrm{H}^{+}+4 \mathrm{e}^{-}=2 \mathrm{H}_{2}
\end{aligned}
$$

\section{G. Hydrogen Tank}

For long-term storage, Hydrogen storage systems have an economic and technical advantage over batteries. Of all chemical fuels, Hydrogen has the highest heating value per mass. The physical-based compressed gas technology in durable tanks has been employed in this study. According to the literature, this technique is the most mature and cost-effective hydrogen storage technology and is appropriate for the scale and purpose of the scenarios [18].

\section{H. Fuel Cell (FC)}

A fuel cell is an electrochemical engine that uses oxidation/reduction reactions to generate energy. An electrolyte membrane is placed between two catalyst-coated electrodes of a fuel cell (anode and cathode). Hydrogen and Oxygen are mixed to produce energy in fuel cells, essentially the reverse of electrolysis. Hydrogen gas oxidizes in the anode region, releasing electrons and producing $\mathrm{H}^{+}$ions. Equation (2) explains the working principle of fuel cells:

$$
\begin{aligned}
& \text { Anode : } 4 \mathrm{H}^{+}+4 \mathrm{e} \rrbracket=2 \mathrm{H}_{2} \\
& \text { Cathode: } 2 \mathrm{H}_{2} \mathrm{O} \rightarrow \mathrm{O}_{2}+4 \mathrm{H}^{+}+4 \mathrm{e}^{-} \\
& \text {Overall : } 2 \mathrm{H}_{2} \mathrm{O}+\mathrm{H} \mathbb{\mathrm { O }}+4 \mathrm{e} \rrbracket \rightarrow 2 \mathrm{H}_{2}+\mathrm{O}_{2}+4 \mathrm{H} \mathbb{\mathrm { H }}+4 \mathrm{e} \rrbracket
\end{aligned}
$$

\section{Batteries}

The fast charging and discharging capabilities of battery energy storage systems significantly increase the flexibility of power grids. In this study, fast frequency-responsive (FFR) battery storage systems comprised of Li-ion technology has been employed - a string of $3 \mathrm{Li}$ ion batteries to create an 11.1 V DC bus. The FFR batteries help systems deal with transitory power quality challenges brought on by the changing PV power output characteristic. FFR Li-ion batteries are now widely used for their extended cycle life and fast-charging characteristics [14]. 
The converter consists of both the inverter and rectifier technologies. Solar PV arrays generate DC power, which must be transformed into AC power using inverters. In this study, a converter with a round-trip efficiency of $90 \%$ has been considered.

\section{Results Analysis}

The initial phase of the simulation study comprised a system optimization considering a diesel generator to meet the electricity demand. This situation could be considered as the base case. Then, more PV modules have been gradually added along with battery energy devices to increase the renewable energy share. Later on, Hydrogen was brought in, and finally, a whole hybrid system design was configured.

The local market analysis led to determine the nominal interest rate, inflation rate and the per-unit capital cost of each system component. Accordingly, operation and maintenance costs, component capacity or size, efficiency, dispatch strategy, generator control, technical constraints were used as inputs to the system study based on the local context.

Table I shows the outcome of the energy flow simulation study for the base case scenario. To meet the load demand, several generator capacities were considered. For example, the overall capacity of the DG was chosen as $800 \mathrm{~kW}$ and $810 \mathrm{~kW}$ for the first (Run 1) and second (Run 2) simulation study instances, respectively. The outcome shows that using $800 \mathrm{~kW}$ DG incurs no excess electricity, whereas increasing the DG capacity by $10 \mathrm{~kW}$ only incurs excess electricity as well as the COE. This reveals that $800 \mathrm{~kW}$ is the optimal solution for the base case scenario.

Table II presents the parameter outcomes for several case scenarios of the DG-PV-Battery hybrid design. For this design, several strategies with varying PV and battery capacity were studied. It is observed that when the DG share is lower (Run 1), the surplus electricity climbs to $37 \%$. When PV and DG share the same amount of generation, both the ECE and COE drop to $16.9 \%$ and 20.22 BDT*, respectively. It has also been observed that if the DG share is less than $50 \%$, both the ECE and COE increase. If the microgrid can not feed the excess electricity back to the national grid through a feed-in-tariff scheme, the Run 3, 4 and 5 combinations do not provide a technically and economically feasible solution.

Table §: System parameter outcomes for the base case scenario

\begin{tabular}{|llllll|}
\hline & DG & & ECE & & COE \\
\cline { 2 - 6 } & kWh/year & $\%$ & kWh/year & $\%$ & BDT* \\
\hline Run 1 & $2,901,093$ & 100 & 0 & 0 & 23.08 \\
\hline Run 2 & $2,901,117$ & 100 & 24.2 & 0.0008 & 24.41 \\
\hline
\end{tabular}

*1.00 BDT $=0.012$ USD

Table II: System parameter outcomes for DG-PV-Battery scenario

\begin{tabular}{|lllllllll|}
\hline - & PV & & DG & & Battery & ECE & & COE \\
& kWh/ & $\%$ & kWh/ & $\%$ & kWh/ & kWh/ & $\%$ & BDT* \\
& year & & year & & year & year & & \\
\hline Run 1 & 283,083 & 61 & 180,871 & 39 & 21.5 & 171,852 & 37 & 21.29 \\
\hline Run 2 & $1,784,011$ & 50 & $1,785,067$ & 50 & 37,486 & 604,542 & 17 & 20.22 \\
\hline Run 3 & $2,023,630$ & 54 & $1,750,522$ & 46 & 71,123 & 802,355 & 21 & 21.39 \\
\hline Run 4 & $2,293,448$ & 58 & $1,696,449$ & 43 & 81,696 & $1,013,586$ & 25 & 21.50 \\
\hline Run 5 & $2,293,448$ & 58 & $1,696,449$ & 43 & 81,696 & $1,013,586$ & 25 & 21.50 \\
\hline
\end{tabular}

$* 1.00 \mathrm{BDT}=0.012$ USD

System parameter outcomes for DG-PV-Hydrogen scenarios are shown in Table III. It is observed that the ECE in this scenario for all the runs is lower than in the previous scenario (Table II). In Table III, Run 5, where PV with the maximum rating (1700 kW) was used, the ECE 
to only $0.09 \%$. However, the fuel cell (FC) capacity factor (CF) is relatively low (1.81\%), which is not the desired outcome. It is understood that the ECE amount goes up as the CF of the FC gets higher and vice versa. Hence for decision-making, if the COE is prioritized over ECE, then from Table III, Run 1 is recommended. However, if it is the other way around, then Run 5 is preferred. This calls for careful design and decision-making and policy recommendations for a robust feed-in-tariff scheme.

The challenging issues in the previous scenarios do not seem to exist in the DG-PV-Hydrogen-Battery scenario. The system parameter outcomes for the DG-PV-Hydrogen-Battery scenario is presented in Table IV. According to the table, for all the runs, except Run 2, the PV share is higher than $50 \%$. The CF of the FC and electrolyzer is $2.87 \%$ and $24.8 \%$, respectively, however, with an ECE of $16.2 \%$. The lowest ECE and COE are observed in Run 2, where CF of the FC and electrolyzer are lower among other runs, and solar PV share is also the lowest among other options. Hence, looking at the results in table IV, the researchers recommend Run 3 as the optimal solution, where a tradeoff has been considered among the parameters, such as COE (21.39 BDT $\approx$ US\$0.25), ECE (5.96\%), the share of PV generation (52.7\%), and CF Electrolyzer (21.1\%) and FC (2.27\%).

While promoting renewable energy-based microgrids in off-grid mode, the COE becomes a significant concern in developing countries. If a robust feed-in-tariff scheme exists, the varying amount of daily surplus electricity produced from the renewable sources could be fed back to the grid. In this study, these factors were considered while recommending the optimal solution for a DG-PV-Hydrogen-Battery hybrid microgrid design for a remote community in Bangladesh. It could create an argument from the results obtained that the COE could further be reduced if the PV share and fuel cell and electrolyzer interactions could be compromised. However, this would contradict the study objective to increase the penetration level of renewable energy in the microgrid, meeting all technical and non-technical constraints.

In [19], a comprehensive PV-Hydrogen FC system for a remote Bangladeshi community has been modelled and analyzed. Because the system architecture and a few assumptions have similarities, both the outcome of the studies have been compared. This study showcases improved and approachable outcomes due to more advanced analysis and adopting specific generation philosophy. However, hybrid microgrid design and considerations are case-specific solutions based on the local context; hence a generalization of a solution is not recommended. The comparison study of both simulation outcomes is shown in Table V. As the costs and associated technical features of a hybrid microgrid see a decreasing pattern day by day, the COE of both these studies can not be directly judged. However, it can be stated that a hybrid microgrid comprising PV, Hydrogen and battery technologies are economically feasible in remote communities in Bangladesh.

Table 邓: System parameter outcomes for DG-PV-Hydrogen scenario

\begin{tabular}{|c|c|c|c|c|c|c|c|c|c|c|c|}
\hline \multirow[t]{2}{*}{ 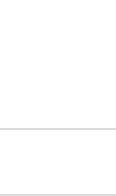 } & \multicolumn{2}{|l|}{ PV } & \multicolumn{2}{|l|}{ DG } & \multicolumn{2}{|l|}{ FC } & \multicolumn{2}{|c|}{ Excess Electricity } & COE & $\begin{array}{l}\text { Electrolyzer } \\
\text { CF }\end{array}$ & $\begin{array}{l}\text { FC } \\
\text { CF }\end{array}$ \\
\hline & kWh/year & $\%$ & kWh/year & $\%$ & kWh/year & $\%$ & kWh/year & $\%$ & BDT* & $\%$ & $\%$ \\
\hline Run 1 & 283,083 & 61.5 & $1,719,546$ & 37.3 & 57,275 & 1.24 & 736,100 & 16.0 & 21.01 & 30.9 & 3.27 \\
\hline Run 2 & 634,038 & 20.1 & $2,424,798$ & 79.1 & 6,522 & 0.213 & 27,614 & 0.901 & 21.77 & 3.64 & 0.372 \\
\hline Run 3 & $2,023,630$ & 50 & $1,977,379$ & 48.8 & 48,870 & 1.21 & 232,451 & 5.74 & 21.90 & 28.3 & 2.79 \\
\hline Run 4 & $2,293,448$ & 53.9 & $1,910,720$ & 44.9 & 52,413 & 1.23 & 377,923 & 8.88 & 21.85 & 30.2 & 2.99 \\
\hline Run 5 & $2,293,448$ & 54 & $1,907,526$ & 44.9 & 47,615 & 1.12 & 386,105 & 0.09 & 21.93 & 29.7 & 1.81 \\
\hline
\end{tabular}

*1.00 BDT $=0.012$ USD

Table IV: System parameter outcomes for DG-PV-Hydrogen-Battery scenario 


\begin{tabular}{|c|c|c|c|c|c|c|c|c|c|c|c|c|}
\hline & \multicolumn{2}{|l|}{ PV } & \multicolumn{2}{|l|}{ DG } & \multicolumn{2}{|l|}{ FC } & \multirow{2}{*}{$\begin{array}{l}\text { Battery } \\
\text { kWh/year }\end{array}$} & \multicolumn{2}{|c|}{ Excess Electricity } & \multirow{2}{*}{$\begin{array}{l}\text { COE } \\
\text { BDT* }\end{array}$} & \multirow{2}{*}{$\begin{array}{l}\text { Electrolyzer } \\
\text { CF } \\
\%\end{array}$} & \multirow{2}{*}{$\begin{array}{l}\mathrm{FC} \\
\mathrm{CF} \\
\%\end{array}$} \\
\hline & kWh/year & $\%$ & kWh/year & $\%$ & kWh/year & $\%$ & & kWh/year & $\%$ & & & \\
\hline $\begin{array}{l}\text { Run } \\
1\end{array}$ & $2,833,083$ & 63.8 & $1,556,743$ & 35.1 & 50,301 & 1.13 & 230,888 & 720,287 & 16.2 & 24.93 & 24.8 & 2.87 \\
\hline $\begin{array}{l}\text { Run } \\
2\end{array}$ & $1,650,699$ & 47.5 & $1,798,302$ & 51.7 & 27,588 & 0.794 & 4,376 & 27,907 & 2.24 & 20.28 & 14.2 & 1.57 \\
\hline $\begin{array}{l}\text { Run } \\
3\end{array}$ & $2,023,630$ & 52.7 & $1,774,607$ & 46.2 & 39,736 & 1.04 & 5,736 & 228,816 & 5.96 & 21.39 & 21.1 & 2.27 \\
\hline $\begin{array}{l}\text { Run } \\
\mathbf{4}\end{array}$ & $2,293,448$ & 56.1 & $1,749,950$ & 42.8 & 45,918 & 1.12 & 2,285 & 376,322 & 9.20 & 21.55 & 24.5 & 2.62 \\
\hline $\begin{array}{l}\text { Run } \\
\mathbf{5}\end{array}$ & $2,293,448$ & 56.7 & $1,711,540$ & 42.3 & 43,446 & 1.07 & 12,968 & 370,122 & 9.14 & 21.62 & 23.2 & 1.65 \\
\hline
\end{tabular}

*1.00 BDT $=0.012$ USD

\section{Conclusion}

The techno-economic feasibility of using Hydrogen as a long-duration and long-term energy storage for a standalone/off-grid microgrid in a specific area of Bangladesh is investigated in this study. A diesel-PV-Hydrogen-based, a diesel-PV-battery-based and a hybrid diesel-PVHydrogen-battery-based microgrid have been evaluated and compared with the base case scenario, which is a conventional diesel-based system. The hybrid combination has been proved to be a techno-economically feasible solution to promote renewable energy resourcebased microgrids in Bangladesh. Another reason why Hydrogen has been chosen as a part of the potential solution is that Hydrogen can be blended with natural gas and used for cooking. This may be done by a pipeline, similar to how the UK now get natural gas [20]. Furthermore, a cost-effective standalone microgrid would encourage green electrification through renewable energy resources while easing the burden of grid expansion, which might be costly for the local utility. This would pave the way for sustainable development while also ensuring regional energy security.

Table V: Comparative Analysis with Similar Test Case

\begin{tabular}{|lll|}
\hline Parameters & Analysis in [19] & This Study \\
\hline Annual Energy Supply (kWh) & 131,083 & $3,837,973$ \\
\hline COE (BDT*) & 41.316 & $\mathbf{2 1 . 3 9}$ \\
\hline Total diesel generator capacity (kWh/year) & 0 & $1,774,607$ \\
\hline PV capacity (kWh/year) & 105,059 & $2,023,630$ \\
\hline Fuel cell capacity (kWh/year) & 26,024 & 39,736 \\
\hline
\end{tabular}

*1.00 BDT $=0.012$ USD

The proposed hybrid system might incur a high installation cost than a conventional system. However, with the advances of time as technology cost decreases, the overall costing for the proposed system will decrease in the foreseeable future. Compared to other systems available in the literature, the proposed system also reduces surplus energy while prolonging system autonomy through Hydrogen storage. This is a safe application of Hydrogen that expands the ways in which it can be used as storage backup along with batteries. Furthermore, $\mathrm{CO}_{2}$ emissions from the suggested system are relatively low, whereas $\mathrm{CO}_{2}$ emissions from traditional diesel-based systems are concerning. As a result, the proposed hydrogen-based microgrid can be considered an unconventional answer to the upcoming energy issue \& environmental threat.

\section{Declarations}

The authors declare no competing interests.

\section{References}


1. T. B. Johansson, A. Patwardhan, N. Nakicenovic, and L. Gomez-Echeverri, "Global Energy Assessment: Toward a Sustainable Future, Cambridge University Press, UK.," p. 1884, 2012.

2. K. Alanne and S. Cao, "An overview of the concept and technology of ubiquitous energy," Appl. Energy, vol. 238, no. January, pp. 284302, 2019, doi: 10.1016/j.apenergy.2019.01.100.

3. F. Dawood, M. Anda, and G. M. Shafiullah, "Hydrogen production for energy: An overview," Int. J. Hydrogen Energy, vol. 45, no. 7, pp. 3847-3869, 2020, doi: 10.1016/j.ijhydene.2019.12.059.

4. A. H A Alwaeli, H. A Kazem, and M. T Chaichan, "Review and design of a standalone PV system performance," Int. J. Comput. Appl. Sci., vol. 1, no. 1, pp. 1-6, 2016, doi: 10.24842/1611/0001.

5. J. Andersson and S. Grönkvist, “Large-scale storage of hydrogen,” Int. J. Hydrogen Energy, vol. 44, no. 23, pp. 11901-11919, 2019, doi: 10.1016/j.ijhydene.2019.03.063.

6. A. Otto, M. Robinius, T. Grube, S. Schiebahn, A. Praktiknjo, and D. Stolten, "Power-to-steel: Reducing CO2 through the integration of renewable energy and hydrogen into the German steel industry," Energies, vol. 10, no. 4, 2017, doi: 10.3390/en10040451.

7. S. Islam and M. Z. R. Khan, "A Review of Energy Sector of Bangladesh," Energy Procedia, vol. 110, pp. 611-618, Mar. 2017, doi: 10.1016/J.EGYPRO.2017.03.193.

8. T. Khadem, S. M. B. Billah, S. Barua, and M. S. Hossain, "HOMER based hydrogen fuel cell system design for irrigation in Bangladesh," 4th Int. Conf. Adv. Electr. Eng. ICAEE 2017, vol. 2018-Janua, no. September, pp. 445-449, 2017, doi: 10.1109/ICAEE.2017.8255397.

9. S. K. Nandi and H. R. Ghosh, "A wind-PV-battery hybrid power system at Sitakunda in Bangladesh," Energy Policy, vol. 37, no. 9, pp. 3659-3664, 2009, doi: 10.1016/j.enpol.2009.04.039.

10. M. E. Karim, R. Karim, M. T. Islam, F. Muhammad-Sukki, N. A. Bani, and M. N. Muhtazaruddin, "Renewable energy for sustainable growth and development: An evaluation of law and policy of Bangladesh," Sustain., vol. 11, no. 20, 2019, doi: 10.3390/su11205774.

11. Jamal, Taskin, Tania Urmee, and G. M. Shafiullah. "Planning of off-grid power supply systems in remote areas using multi-criteria decision analysis." Energy 201 (2020): 117580.

12. F. Dawood, G. M. Shafiullah, and M. Anda, "Stand-alone microgrid with $100 \%$ renewable energy: A case study with hybrid solar pvbattery-hydrogen," Sustain., vol. 12, no. 5, 2020, doi: 10.3390/su12052047.

13. Y. Zhang, A. Lundblad, P. E. Campana, and J. Yan, "Comparative Study of Battery Storage and Hydrogen Storage to Increase Photovoltaic Self-sufficiency in a Residential Building of Sweden," Energy Procedia, vol. 103, no. April, pp. 268-273, 2016, doi: 10.1016/j.egypro.2016.11.284.

14. Jamal, Taskin, G. M. Shafiullah, Craig Carter, and Tania Urmee. "A comprehensive techno-economic and power quality analysis of a remote PV-diesel system in Australia." Renewable Energy and Environmental Sustainability 2 (2017): 24

15. Arif, Shaila, Ata E. Rabbi, Taskin Jamal, and Tareq Aziz. "Behavioural Study of a Remote Power System with High PV Penetration During a State of Emergency." In 2020 International Conference on Smart Grids and Energy Systems (SGES), pp. 590-595. IEEE, 2020.

16. Bangladesh National Portal, information \& services in a single window, Available online: https://bangladesh.gov.bd/index.php (accessed Aug. 23, 2021).

17. HOMER Pro (2021, July 10). Solar Radiation Data. Available: https://www.homerenergy.com/products/pro/docs/latest/finding_data_to_run_homer.html

18. Sankir, M.; Sankir, N.D. (Eds.)Hydrogen Storage Technologies; John Wiley \& Sons, Inc.: Hoboken, NJ, USA, 2018

19. K. K. Hossain and T. Jamal, "Solar PV- Hydrogen Fuel cell system for electrification of a remote village in Bangladesh," Proc. 2015 3rd Int. Conf. Adv. Electr. Eng. ICAEE 2015, pp. 22-25, 2016, doi: 10.1109/ICAEE.2015.7506787.

20. Evangelia Topriska, "Hydrogen could become the new fuel for cooking - here's how", September 29, 2016. Available online: https://theconversation.com/hydrogen-could-become-the-new-fuel-for-cooking-heres-how-66241

\section{Figures}




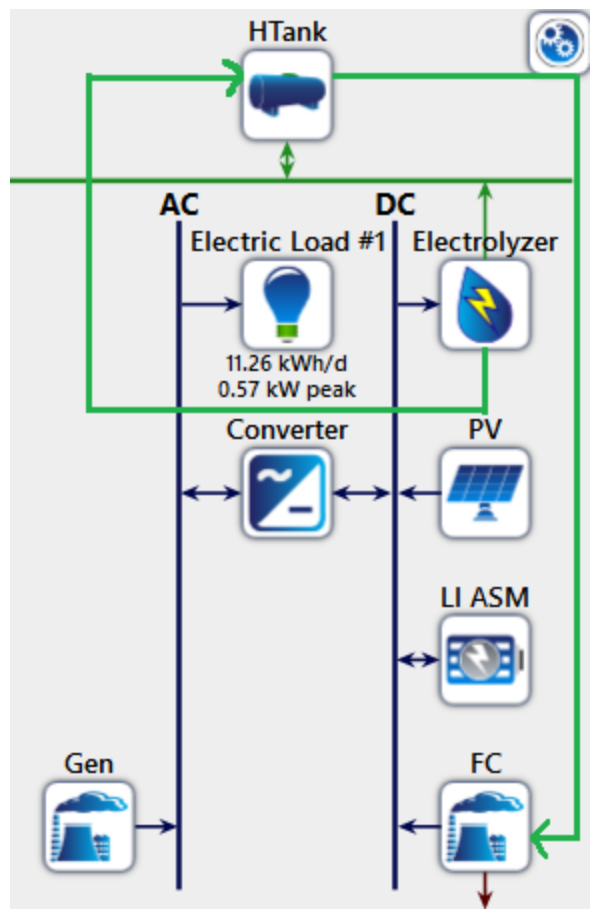

Figure 1

Schematic diagram of the proposed system

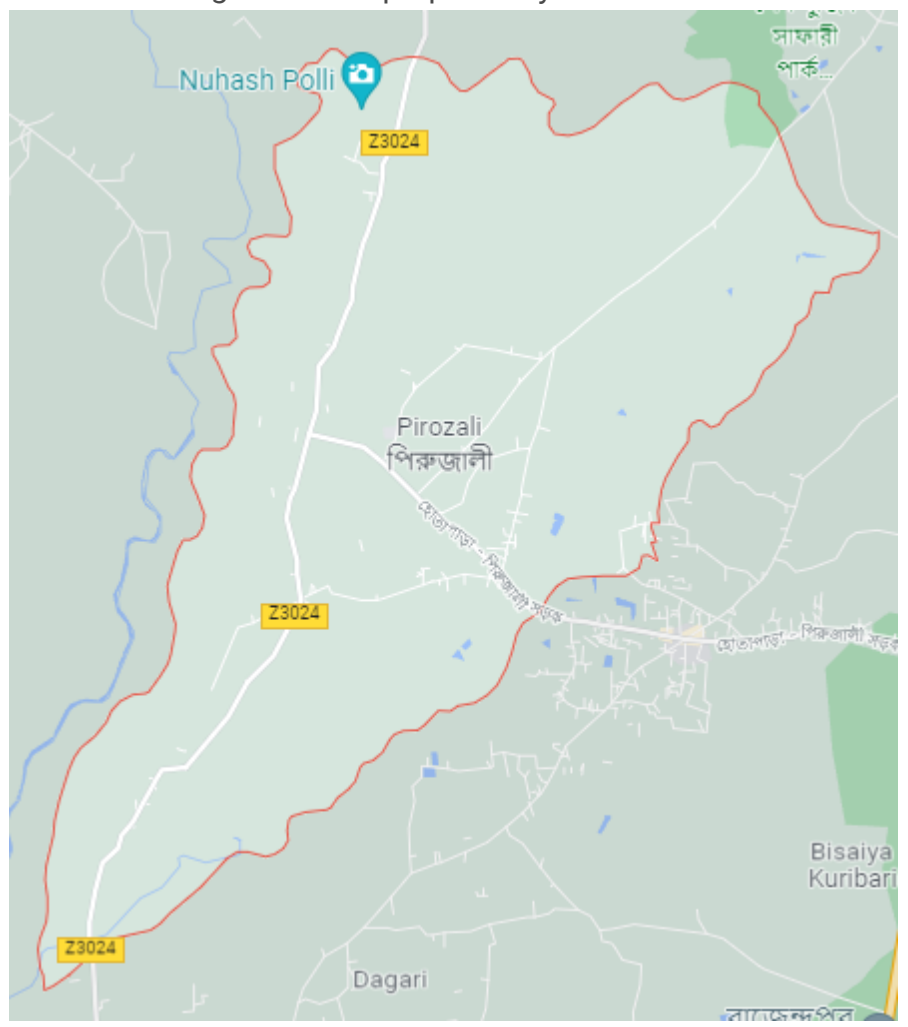

Figure 2

Map of the selected location (Pirujali) 
Yearly Profle

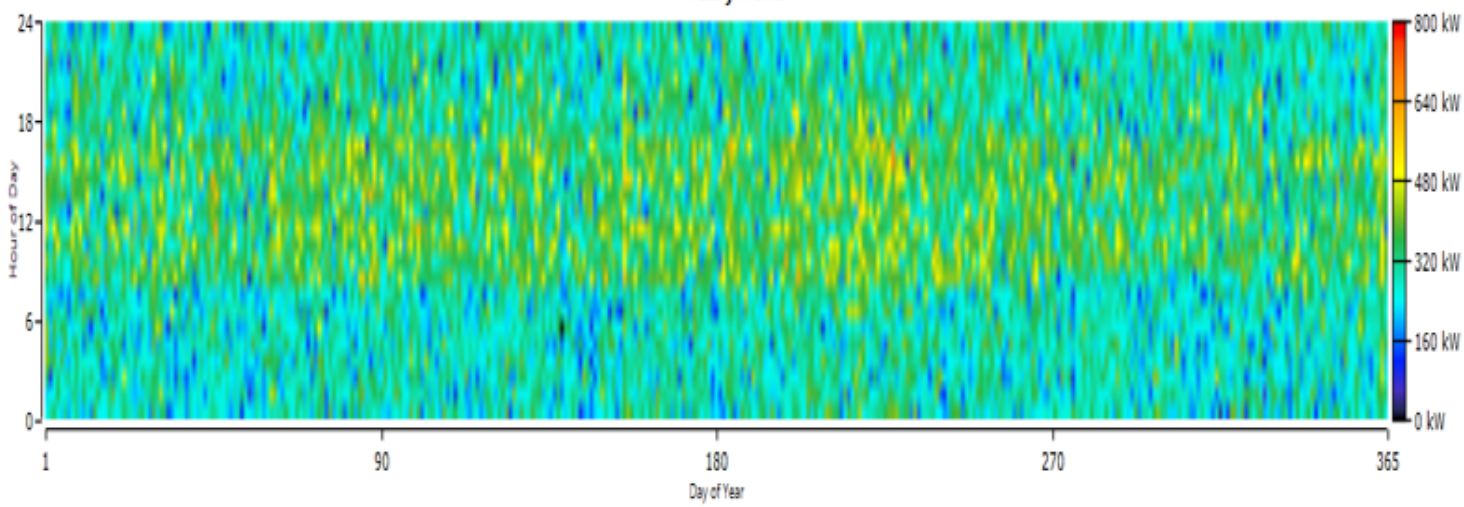

(a)

Daily Profile

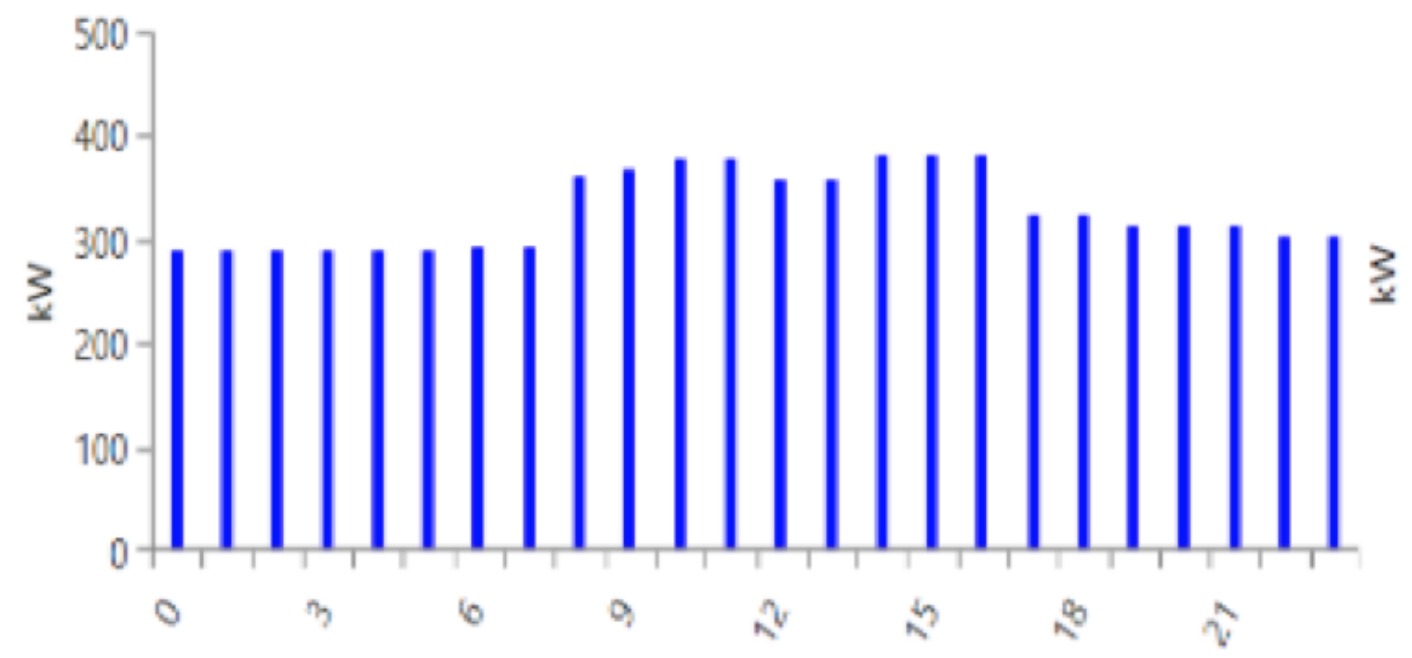

(b)

Figure 3

(a) Annual and (b) hourly-average daily load profile

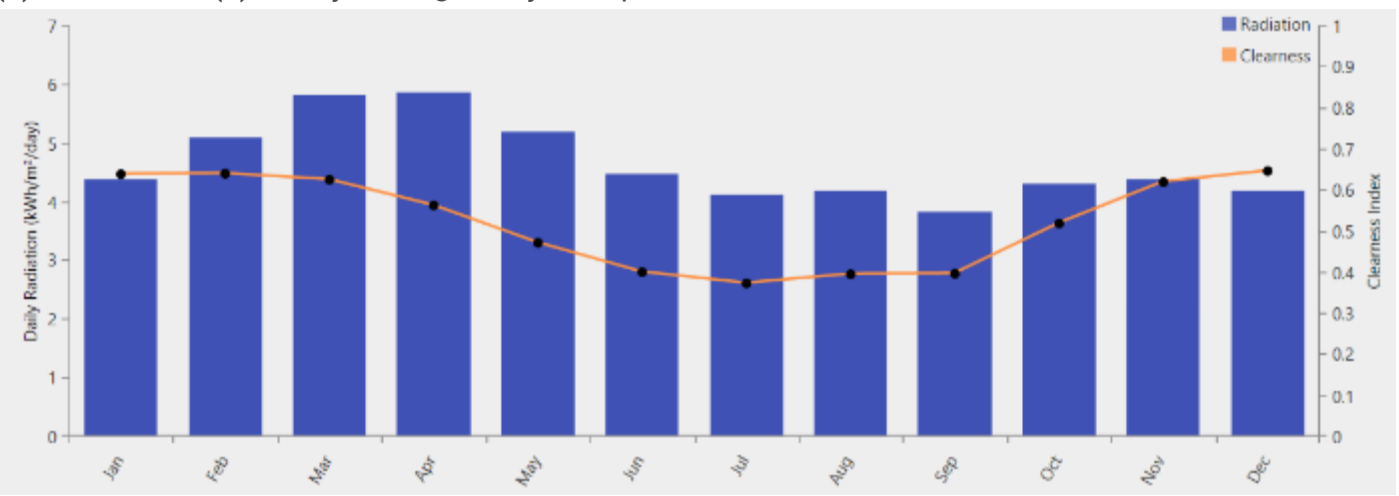

Figure 4

Annual solar irradiance profile in Pirozali, Gazipur 